Divorced and Unemployed: the Declining Association between Two Critical Lifecourse States in the UK, 1984-2017

DIAL Working Paper Series 16/2019

Lewis R. Anderson, Christiaan W.S. Monden, Erzsebet Bukodi

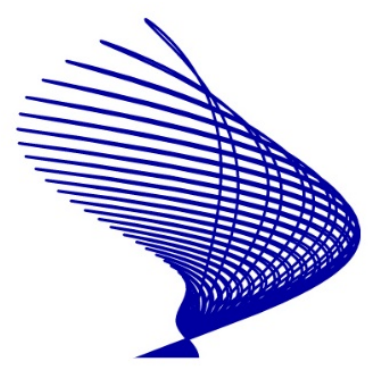

NORFACE

NETWORK 


\title{
Divorced and Unemployed: the Declining Association between Two Critical Lifecourse States in the UK, 1984-2017
}

\author{
Lewis R. Anderson ${ }^{1}$, Christiaan W.S. Monden ${ }^{2}$, and \\ Erzsebet Bukodi ${ }^{3}$
}

\begin{abstract}
Individuals exposed to both job loss and marital dissolution are likely to be highly disadvantaged, having experienced stresses and losses in the two primary domains of life. Moreover, recent literature finds that exposure to one event tends to increase risk of the other. However, next to nothing is known about the size or composition - or changes therein of the divorced/separated and unemployed (DSU) subpopulation. Using large, nationally representative, repeated cross-sectional datasets extending back to 1984, we aim to fill this gap for the UK. We give a descriptive account of the prevalence and social distribution of DSU, and of the cross-sectional association between its two component states: among which groups, by education and gender, does being either divorced/separated or unemployed most strongly imply a heightened risk of also being the other, and how has this changed over time? We find stable and strong educational inequality in DSU, while the gender gap has narrowed and recently closed. The association between the two states is stronger among men; has weakened strikingly over the time period we consider, for both men and, especially, women; and is educationally stratified among men but not women. Contrary to expectations, higher-educated men in one of the two states are most likely to also be in the other. Possible explanations and further questions are discussed. In particular, we highlight the possibility that over this time period the divorced/separated have become more like the general population, rather than a negatively selected subgroup among whom unemployment is a particular risk.
\end{abstract}

Keywords: divorced, marital dissolution, unemployed, job loss, repartnering, cumulative disadvantage

1. Corresponding author. Nuffield College and Department of Sociology, University of Oxford, lewis.anderson@sociology.ox.ac.uk.

2. Nuffield College and Department of Sociology, University of Oxford.

3. Nuffield College and Department of Social Policy and Intervention, University of Oxford. 


\section{Acknowledgments}

Research reported in this manuscript is part of the project CRITEVENTS, which is part of the joint NORFACE research program "Dynamics of Inequality Across the Life-course" (DIAL). DIAL is funded by the European Commission via an ERA-NET Cofund grant (grant number 724363).

We are grateful for the comments and suggestions from those present at the CRITEVENTS project meeting at the European University Institute, Florence, June 2018. We also thank Pepita Barlow, Patrick Präg, Paula Sheppard, Zachary Van Winkle, and Florianne Verkroost for their comments and suggestions.

\section{Online supplemental material}

Supplemental material for this paper can be accessed at: 


\section{Introduction and background}

Most studies which attend to both divorce and job loss ask whether exposure to one event is associated with an increased risk of the other. Prompted, among other considerations, by the many positive answers that have been found to both questions (Blekesaune 2008; Covizzi 2008; Hansen 2005; Jalovaara 2003; Kalmijn 2005; Killewald 2016; Lampard 1994), the aim of this paper is to explore the co-prevalence of being divorced or separated and being unemployed. Since marital dissolution and unemployment occur in the two primary domains of life - home and work - the two events together may have implications for just about every aspect of an individual's wellbeing. Whatever outcomes job loss may leave untouched - for instance, a fulfilling relationship with one's partner - marital dissolution probably will not (Brand 2015; Leopold 2018). In other words, individuals exposed to both job loss and marital dissolution are likely to be distinctly disadvantaged. Surprisingly little is known about this potentially precarious state, its distribution in the population, and changes over time.

The co-prevalence of the two states refers to a frequency or proportion which may be viewed as having two parts: the portion expected to arise from chance alone - given that there are a certain number of divorced/separated individuals and a certain number of unemployed individuals, and the two are not mutually exclusive - and the portion beyond this. This second part reflects the cross-sectional association between being divorced/separated and being unemployed at a given point in time. The strength of this cross-sectional association, and its distribution between sociodemographic groups and over time, is the focus of this paper: among which groups does being either divorced/separated or unemployed most strongly imply a heightened risk of also being the other?

The groups to which we pay particular attention are those formed by men and women with differing levels of education. Education is robustly associated with the risk of 
unemployment (Brand 2015), although its association with divorce is far more complicated, and may vary by gender (Kalmijn, de Graaf, and Poortman 2004). With regard to both men's and women's education, different countries variously show positive (Blossfeld et al. 1995), null (Bracher et al. 1993), and negative (Lyngstad 2004) gradients in divorce. Looking across marriage cohorts from the 1960s to 1990s, Härkönen and Dronkers (2006) find that in all of the nine (out of seventeen) Western countries where the educational gradient in divorce has changed over time, it has become more negative.

We investigate the co-prevalence between being divorced/separated and being unemployed in the context of the UK. The proportion divorced/separated is likely to be relatively high in the UK, given its somewhat high crude divorce rate over the last halfcentury in comparison with most European nations (Eurostat 2018a). The divorce rate rose rapidly from the mid-1960s and remained high until a fall in the last decade or so (ONS 2017), making it rather widespread and unremarkable. Indeed, cultural and economic barriers to divorce are low. There are few Catholics, or members of any other religion with a strong prohibition against divorce. Female labour market participation and educational enrolment are high, lowering the relative economic costs of divorce for many women. In these respects the UK resembles much of northern and western Europe (Wagner and Weiß 2006). Though UK data were not available to Härkönen and Dronkers (2006), other evidence indicates that in the UK the gradient has also become more negative, and in fact switched from positive to negative (Chan and Halpin 2008), a result also found for Sweden (Hoem 1997).

The UK unemployment rate was high in the early 1980s, and the country experienced another recession in the early 1990s, again elevating unemployment. Since then however, and particularly in terms of its recovery from the late-2000s financial crisis, the UK has seen relatively low unemployment compared to its European neighbours (Eurostat 2018b). It may then be that the unemployed are increasingly negatively selected, especially in terms of 
education. This, coupled with the negative educational gradient in divorce, may have led to an increase in the co-prevalence of being divorced/separated and being unemployed, among the less educated in particular.

We focus on the states of being divorced/separated and being unemployed rather than the events which represent entry into (or exit from) them. The distribution of marital dissolution following job loss (and vice versa) may differ from the distribution of persistence in, and exit from, the state of being divorced/separated and unemployed (hereafter, DSU). It could be, for instance, that men experience more spells of DSU than women on average, but the duration of these spells is much longer among women. The co-prevalence we track maps out an understudied and disadvantaged subpopulation, capturing the outcome of the interplay between the various factors which predispose individuals to unemployment and/or divorce/separation, which affect the likelihood of divorce or separation leading to unemployment (or the reverse), and which affect the likelihood of re-employment or repartnering. Rather than describe which groups are at risk of entry into or exit from DSU, we identify the groups most likely to be living under exposure to DSU at a given moment, which, as we argue below, is likely to be an especially vulnerable state. In this way our paper builds upon and brings together the existing literatures linking job loss and marital dissolution, and those exploring repartnering and transitions out of unemployment.

We therefore address the following research questions: (a) What proportion of the adult UK population are DSU? (b) To what extent is the risk of being DSU different for men and women and stratified by education? (c) How strong is the cross-sectional association between the two component states, and how does this vary by gender and education? In each case we also explore how our findings vary over time, using annual data from 1984-2017. This paper is exploratory and descriptive: we follow Merton's (1987) injunction, situated by 
Goldthorpe as 'the first aim of a population science' (Goldthorpe 2016: 14), to robustly establish the phenomena.

In the next sections we add further motivation for this paper and draw on previous research to articulate our expectations. We then describe the data, measures and methods. This is followed by results, and finally a discussion in which potential explanations for the observed results are discussed, and further questions identified.

\subsection{DSU as an outcome of interest}

Theoretically, the state of being DSU is one of extreme disadvantage. Each of the two states considered separately is associated with low wellbeing and implies previous exposure to a stressful loss event (Dolan, Peasgood, and White 2008; Kalmijn 2005), but there are reasons to view the co-prevalence of the two as especially detrimental.

First, the two are likely to have interactive impacts on several key outcomes, constituting a form of cumulative disadvantage (DiPrete and Eirich 2006). Income is one example. Particularly in more liberal welfare regimes such as the UK, partner's income is an important buffer following job loss (Ehlert 2012). Without a partner to provide this compensation, one's vulnerability to the effect of job loss on income is greater. Health is another: among US men, a large study found that work stressors (including being fired or laid off, or problems getting a new job) were associated with increased risk of all-cause mortality among the divorced but not among the married (Matthews and Gump 2002).

Second, the losses of both employment and marriage deprive individuals of two relatively independent sources of coping resources. Marital dissolution implies the loss of the partner's socioemotional support, social network, and contribution to household income and domestic labour. Job loss implies not only a substantial reduction in own income and 
economic security, but also the loss of important psychosocial bases of wellbeing such as skill use, social networks, status, time structure, and sense of control (Brand 2015; Powdthavee 2012; Price, Choi, and Vinokur 2002). A consistent finding of the stress literature is that the impacts of stressors can be moderated by a sense of control over life, high self-esteem, and social support (Thoits 2010). Employment and marriage contribute to each of these independently, but the loss of both may leave one highly vulnerable to other stressors.

Third, insofar as being in both states makes exit from either more difficult, DSU may constitute something of a wellbeing trap, extending the duration of an already undesirable life-course state. Unemployment is likely to be a major disadvantage among those seeking to repartner. Being divorced/separated in the labour market may be viewed as a signal of negative characteristics by potential employers. In addition, the human capital of spouses influences labour market success (Bernasco, de Graaf, and Ultee 1998); lacking this, and lacking the wider network provided by a partner, may prolong the job search process. Indeed, in the UK, married men are 33 percent more likely to make the transition from unemployed to employed than unmarried men, with other characteristics including age controlled for (Long 2009).

\subsection{Expectations and previous research}

A multiplicity of processes together generate DSU, the cross-sectional association between the two states, stratification in these outcomes, and change over time. We are necessarily agnostic about the diverse range of underlying processes, but seek to give an account of what they produce overall. For this reason, we do not hold strong expectations, but here reflect on 
what are likely to be some of the important mechanisms involved, in the UK context in particular, and the patterns they would imply.

First, the two events giving rise to these states share several individual-level risk factors. As noted above, education has a well-established association with unemployment. Higher levels of education both signal desirable qualities to employers, and reflect the accumulation of human capital. Societies with a positive educational gradient in divorce tend to be those where the cultural and economic barriers are higher; those who get divorced are those with the resources to cope with challenges such as legal barriers, stigma, and a reduction in living standards. However, in countries such as the UK where divorce is a realistic option for far more individuals, its relationship to education reflects other considerations. Among these are that the more educated may possess skills which improve the stability of relationships, and are less likely to suffer financial strain and its destabilising effects; additionally individuals have more to lose financially from divorcing highly-educated partners (Härkönen and Dronkers 2006). As stated above, we expect that DSU will be especially prevalent among the less educated.

Other individual level factors are also relevant. Two of the big five personality traits low conscientiousness and high neuroticism - have been related both to divorce (Boertien and Mortelmans 2017; Solomon and Jackson 2014) and to unemployment (Egan et al. 2017; Uysal and Pohlmeier 2011). Parental divorce is a consistent predictor of marital dissolution (de Graaf and Kalmijn 2006), and the often-accompanying family conflict and singleparenthood increase children's risk of unemployment in adulthood (Caspi et al. 1998). Amato (1996) finds that the intergenerational transmission of divorce is largely mediated through interpersonal behaviour problems; it is plausible that they also mediate a link from parental divorce to unemployment. These factors may each correlate with low education, further reinforcing our expectation that DSU will be educationally stratified. 
Second, there is growing evidence that the unemployed are at increased risk of divorce (Blekesaune 2008; Hansen 2005; Jalovaara 2003; Killewald 2016), and that divorce increases the risk of unemployment (Covizzi 2008; Kalmijn 2005). These effects may be especially strong in the context of the UK's low barriers to divorce and flexible labour market. Evidence points to a gendered pattern in the association of unemployment with subsequent divorce, and in particular to the persistence of the norm of the male breadwinner, rather than to an effect mediated by financial strain or dependence (Killewald 2016; Sayer et al. 2011). This suggests that the association between the two states will be stronger among men than women.

Third, repartnering dynamics will influence the patterns of co-prevalence (de Graaf and Kalmijn 2003), with the unemployed likely to find repartnering more difficult. This again may vary with education, with less educated men having lower odds of repartnering (Shafer and James 2013). Intuitively, even conditional on being unemployed, more-educated individuals might prove more attractive to potential new partners on the basis of their earnings potential. This would imply a stronger cross-sectional association among the less educated.

Men repartner at a higher rate (Wu and Schimmele 2005), which would act to decrease the strength of the association between the two states among men relative to women. While it has been argued that remarriage functions as an especially important strategy for women to overcome the financial consequences of divorce, one test of this hypothesis found support only among women with a low income before divorce (Dewilde and Uunk 2008). To the extent that low education proxies low income, a higher rate of repartnering among less educated unemployed women might partially offset the expected stronger cross-sectional association among less educated women. 
Fourth, the distribution of re-employment matters. Stratification here likely parallels that for unemployment, with the less educated likely to spend longer without a job. An additional consideration is the steep decline in income among women post-divorce (Andreß et al. 2006). This may incentivise a swift return to employment. Indeed, 'there is a consensus that women increase their labour supply substantially after divorce' (Özcan and Breen 2012: 474); among women with better education and higher earnings potential, this strategy might substitute for remarriage 'for the money' and explain the only partial support for that approach found by Dewilde and Uunk (2008). If women are faster to find employment following divorce, this will reduce the cross-sectional association among women relative to men.

Interestingly, there is evidence to suggest that policy reforms - in particular the Working Families Tax Credit - instituted in the UK in 1998 and aimed at 'making work pay' had a pronounced effect on women's post-separation employment. Jenkins (2008) compares BHPS results from 1991-1997 and 1998-2003, and finds a clear increase in the proportion of separated women taking up in-work benefits after separation, and a clear decrease in the proportion taking up unemployment benefits after separation. This implies that the crosssectional association may weaken among women around this point in our time series.

In sum, a wide and complex range of mechanisms generate the outcomes we are interested in. Some of these are expected to act in opposite directions. We have no strong expectations about gender differences, but expect both that DSU will be more prevalent among the less educated, and that the two states will be most strongly associated among the less educated.

Direct evidence on these questions is extremely sparse. Some sequence analysis work on the US and UK has quantified the size of groups with life-course patterns such as 'unstable work, no family' (McMunn et al. 2015). However, since a greater number of 
categories increases the complexity of sequence analysis exponentially, this literature mostly ignores distinctions between unemployment and economic inactivity, and between divorced/separated and never married (Jackson and Berkowitz 2005; McDonough et al. 2015; Worts et al. 2013).

Our current lack of information about the group is also likely attributable in part to sample size constraints - the two component states are each relatively rare. Their coprevalence applies to a group too small to subject to further disaggregation and examination in a detailed cohort or panel survey. We overcome this by turning to the UK Labour Force Survey series, which consistently attains over 100,000 respondents and extends back over several decades. Compared to standard socioeconomic datasets, we trade off longitudinal information and a broad range of measures for the ability to focus on a neglected subpopulation.

\section{Data, measures and methods}

We apply nationally-representative repeated cross-sectional surveys to answer each of our questions for the UK population aged 25-64. We code an annual time series dataset extending from 1984 to 2017 by combining two incarnations of the Labour Force Survey (LFS): the annual LFS, and the Quarterly Labour Force Survey (QLFS). The size of these surveys enables the analysis of gradients in risk for DSU status in spite of this being a small subpopulation.

Our time series begins in 1984, with the introduction of a consistent series of questions aimed at measuring economic status according to the International Labour Organisation (ILO) definitions. The definition of unemployment we use is more inclusive 
than the ILO version, but it is derived from questions designed to measure ILO unemployment.

From 1984-1991 the LFS was conducted annually. In 1992 the survey became the QLFS. The annual LFS data were collected in March-May, so we use the April-June QLFS in each year from 1992-2017. Minor changes to the surveys between years necessitate harmonisation of some of the measures, which we discuss below.

\subsection{Economic status}

Economic status refers to the mutually exclusive categories employed, unemployed, and out of the labour force (OLF). Under the ILO definition, one is unemployed who a) is not employed (i.e. has not worked at least one hour for pay or profit in the previous week), b) would like a paid job, c) is available to start a paid job within two weeks, and d) has undertaken some kind of job-seeking activity within the past four weeks. Someone who has secured a job and is waiting to start is also regarded as unemployed. We use an identical definition of unemployment except that we relax the job-seeking condition d). This means that we include those referred to by Brandolini et al. as the 'potential labour force' (2006: 175) and by others as 'discouraged workers' - those who would like a job and are available to start, but either have not started looking, or last undertook job-seeking activity more than four weeks before the interview. Evidence from 14 European countries, including the UK, indicates that in terms of transition probabilities into employment, this group is clearly distinct from the rest of the OLF population, and generally closer to the ILO unemployed (Brandolini et al. 2006). Despite changes to the survey, by limiting our time series to 1984 onwards we are able to utilise a highly consistent measure of unemployment. As a robustness check, we also report results using the ILO definition of unemployment or, extending back to 
1979, its close approximation (based on a one-week rather than four-week job-seeking activity requirement).

\subsection{Marital status}

Changes to the survey questions on marital status and cohabitation necessarily introduce a small discontinuity into the time series. The result is that for 1988 and earlier, 'divorced/separated' (that is, simply, either of the two self-report marital status categories 'divorced' or 'separated') refers to those who are divorced or separated from their spouse, including those who are currently in a cohabiting relationship (but not remarried). From 1989 onwards, 'divorced/separated' excludes this group and refers only to those who are not currently in a cohabiting relationship, which is to say those who have not repartnered. The exclusion of this divorced/separated-but-currently-cohabiting group is reflected in an $18 \%$ (5\%) decline among men (women) from 1988 to 1989, amidst a rising trend, in the proportion classified as divorced/separated. This slight discontinuity is visible in Figure 1, panels (a) and (b). We assume that these $18 \%$ and 5\% figures (plus a small addition to account for the rising trend line) represent an upper bound for the measurement discontinuity of divorced/separated, insofar as there are no good reasons to believe that proportionately more of the divorced/separated were living in cohabiting relationships in any of the years 1984-1987 than in 1988. This discontinuity does not appear to affect our substantive conclusions. From 1995 onwards, we are able to separately identify, among the divorced/separated, those who are and those who are not currently living in a cohabiting relationship. We compare results for these groups in our supplemental analyses. 


\subsection{Divorced/separated and unemployed (DSU)}

DSU simply refers to individuals who are both divorced/separated and unemployed, as defined above. We here reiterate that we measure states rather than events, and cannot ascertain from these data whether individuals suffered marriage dissolution or job loss first.

\subsection{Education}

We use a relative measure of educational attainment based on individuals' highest reported qualification. For men and women separately, within each five-year birth cohort, the sample is ultimately divided into a top quarter, middle half, and bottom quarter (as closely as possible given the categorical nature of the data, see Figures A1 and A2). Our approach is explicated at length in the supplemental material.

This sex- and cohort-relativisation of education reflects our conceptualisation of education primarily as a positional good in this context - namely labour and marriage markets in which, for the most part, one competes with others of the same sex and similar age. This follows the intuition that, for example, holding A-level qualifications is a far stronger signal of qualities attractive in those markets for someone born in 1930 (a cohort in which around $15 \%$ of men hold greater or equal qualifications) than it is for someone born in 1980 (where the equivalent figure is around 50\%). Accordingly, the former would be in the top approximate quarter by education, while the latter would fall in the middle approximate half of the distribution (see Figure A1). Common understandings of what it means to hold a given highest qualification, such as A-levels, have changed over the longer period across which all individuals in our sample acquired their qualifications. We argue that there is more conceptual consistency in using an artificial top quarter, middle half, and bottom quarter, thus 
taking the shifting distribution of education into account, than there is in using, for instance, degree, any other qualifications, and no qualifications.

\subsection{Methods}

We first plot proportions over time of the three states divorced/separated, unemployed, and DSU. These are presented separately for men and women, and further disaggregated by education. This allows simple visual inspection of the trends in the two critical life-course states and their co-prevalence, as well as their educational stratification over time. To give a clearer picture of this stratification, we then plot time series of age-adjusted risk ratios for DSU by education.

We next turn to the question of how strongly the two component states of DSU are cross-sectionally associated with one another. In other terms, this is the question of how predictive being in one of the two states is of being (also) in the other state (and therefore DSU). To explore this, we plot the odds ratio for the association of the two states, controlling for age, and again disaggregate by sex and educational status. (The odds ratio is preferred to the risk ratio in this context because its property of symmetry allows the more succinct presentation of a single parameter. The two risk ratios for the association of each state with the other are, because of their relatively low prevalence, both extremely similar to one another, and to the odds ratio.) To better understand the trend in this association, we finally plot the proportions unemployed conditional on being divorced/separated, and vice versa. Throughout, weights provided by the LFS are used, which weight data to sub-regional population estimates and then adjust for the estimated age and sex composition by region. 
We also include a robustness check (using the ILO definition of unemployment, as discussed above) and some supplemental analyses. These are both reported in the text, while the accompanying figures can be found in the supplemental material.

\section{Results}

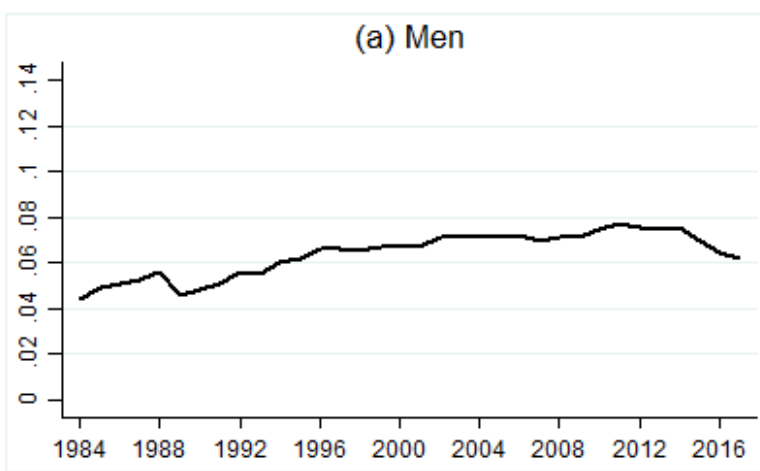

(c) Men, by education

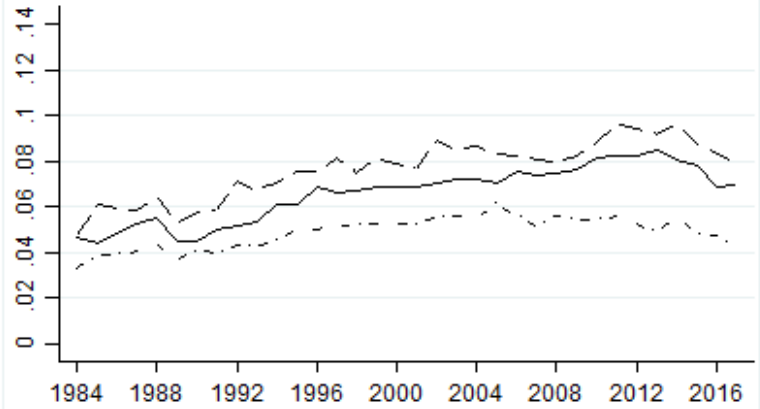

- - - - Bottom quarter (approx)

- Middle half (approx.)

-.... - .... Top quarter (approx.) (b) Women

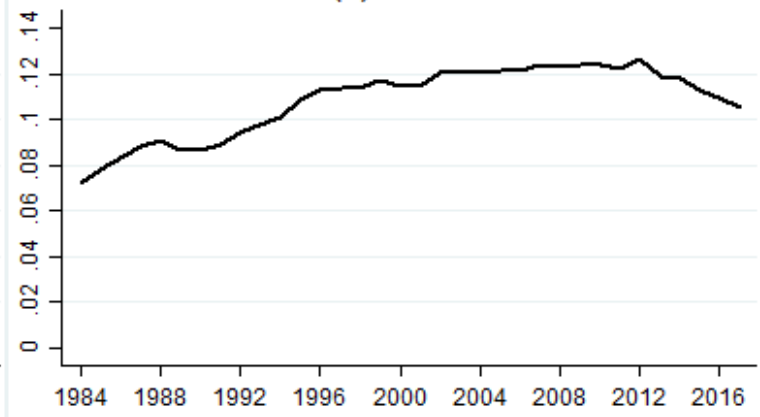

(d) Women, by education

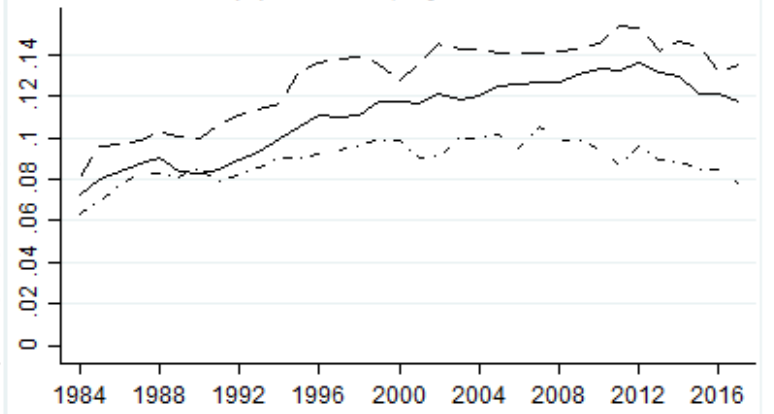

Figure 1 Proportion divorced/separated, by sex and education Source: UK Labour Force Survey. 
(a) Men

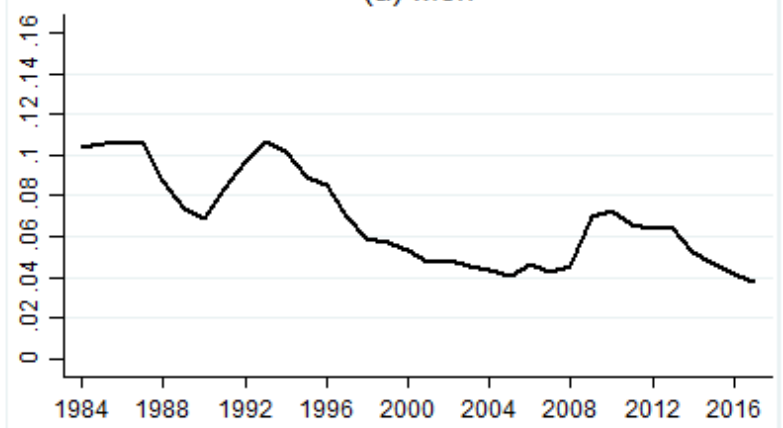

(c) Men, by education

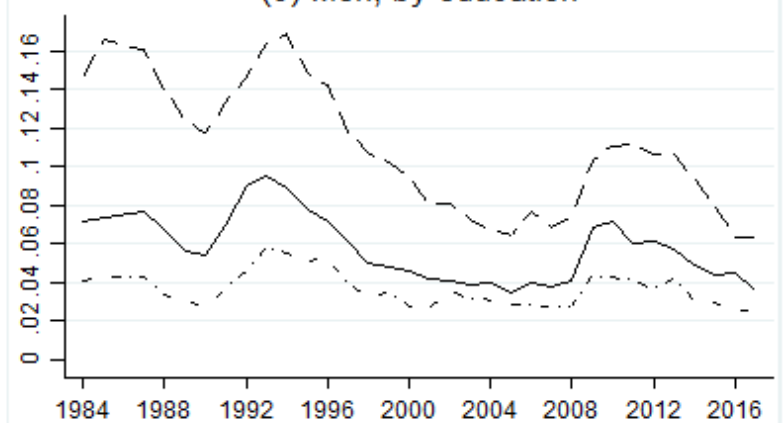

- - - - Bottom quarter (approx.)

- Middle half (approx.)

_. . . - . . . To Tuarter (approx.) (b) Women

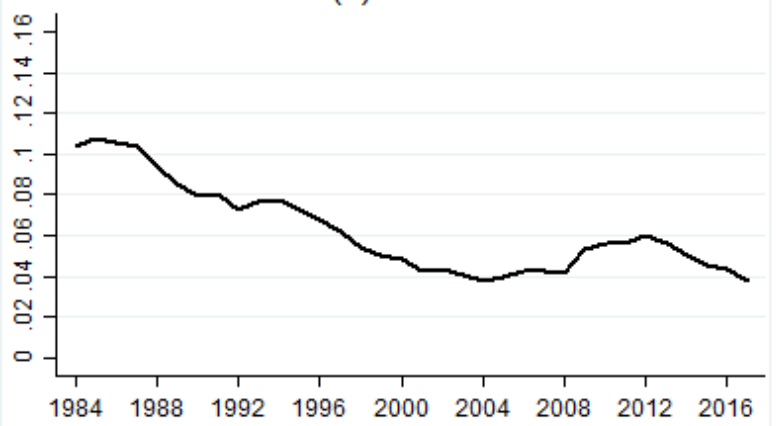

(d) Women, by education

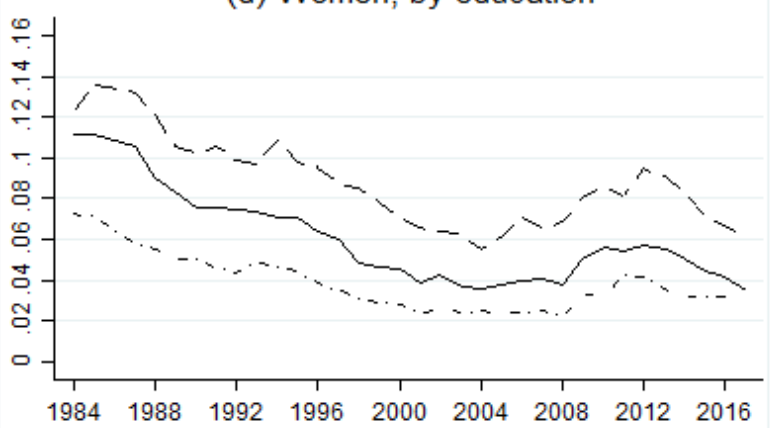

Figure 2 Proportion unemployed, by sex and education Source: UK Labour Force Survey. 
(a) Men

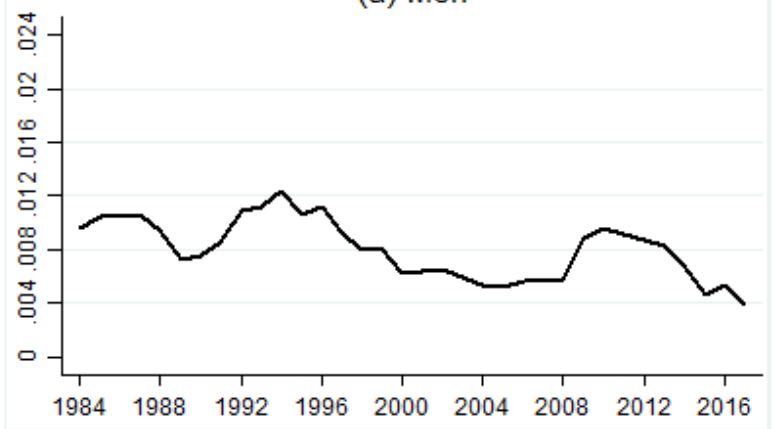

(c) Men, by education

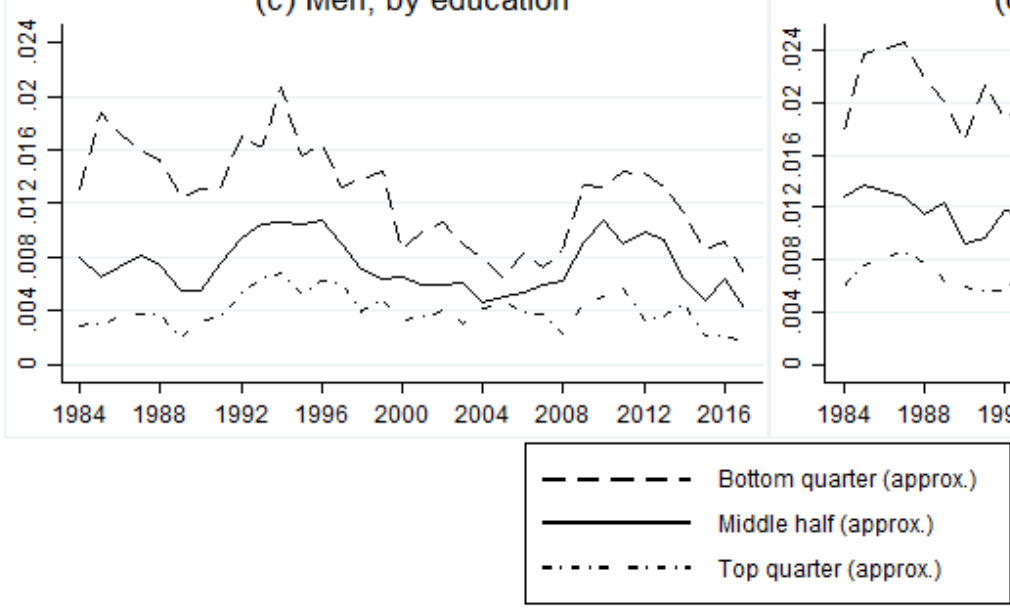

(b) Women

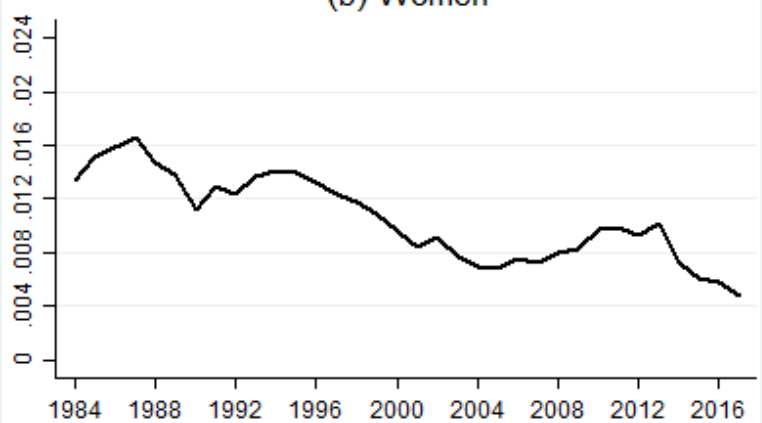

(d) Women, by education

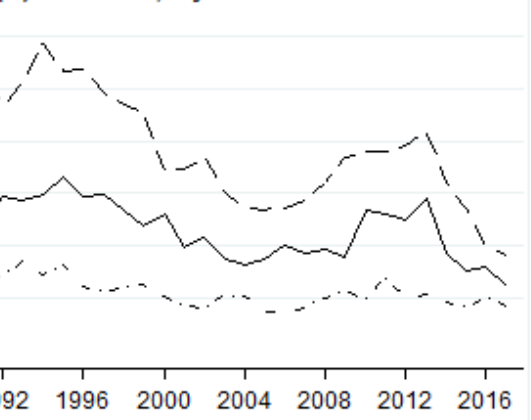

Figure 3 Proportion divorced/separated and unemployed (DSU), by sex and education Source: UK Labour Force Survey.

Figure 1 shows the proportion of those aged 25-64 who are divorced/separated. This is shown separately for men and women in panels (a) and (b), and broken down by education, again for men and women separately, in panels (c) and (d). A clear rising trend in this proportion is evident from 1984 to around 1996, at which point there is a plateau, followed by a more recent decline. This plateau and decline occurs somewhat earlier for the more educated, especially among women. Accordingly, for both men and women there is an increase in the difference in risk between the most educated and the middle half, who had been divorced/separated in similar proportions in the early part of the period. While there is a clear negative educational gradient throughout, it thus becomes stronger through time. The clear overall gender difference reflects a higher frequency and speed of repartnering among men, 
and possibly a higher frequency among women of the preference not to repartner (Kreidl and Hubatková 2017).

Figure 2 shows the proportions unemployed. The early-1980s, early-1990s, and late2000s UK recessions are clearly reflected in three peaks for men, while the middle of these appears to have had a far smaller effect on the female unemployment rate. Since the time series begins in the aftermath of recession, the overall appearance is of a generally steady decline in unemployment, ending at around $4 \%$ for both men and women in 2017 . For both men and women, the most educated have moved somewhat closer to the middle half in terms of their risk of unemployment. For men, the least educated appear to have been especially at risk in the early part of the period, with the inequality narrowing later.

Figure 3 plots the proportions in the state of being DSU. The trends are far more closely correlated with being unemployed than divorced/separated. This is due to spells of unemployment presumably being of shorter duration than the state of being divorced or separated (from 1992-2017, when the measure is available for the ILO-defined unemployed, $44 \%$ reported that they had been unemployed for less than six months). The proportions mirror the declines evident for being unemployed, but moderated by the countervailing rising prevalence of being divorced/separated. The highest co-prevalence among any of the sexeducation groups is $2.4 \%$ among the less-educated women in 1987 . Throughout, women, and in particular those with less education, are the group most at risk of DSU. Despite the high prevalence of being divorced/separated, DSU is at its lowest point in the most recent year, around $0.4 \%$ for both men and women. This equates to an estimated 150,000 DSU individuals. Educational stratification appears stable throughout the period, except that lowereducated men in the 1980s diverge especially from the mid-educated, in line with the result for unemployment alone. 


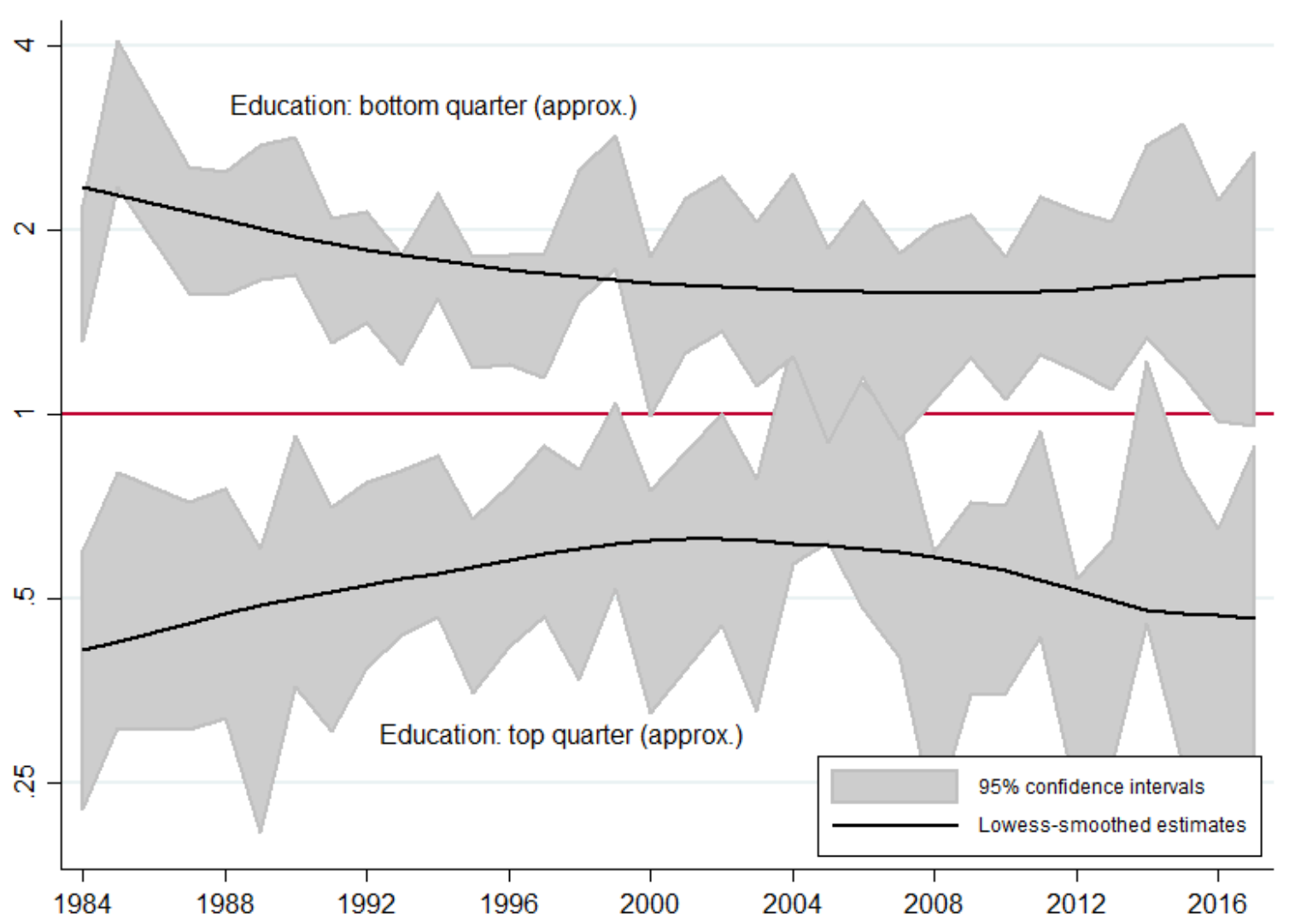

Figure 4 Age-adjusted risk ratios for being divorced/separated and unemployed (DSU), by education, men

Source: UK Labour Force Survey. 


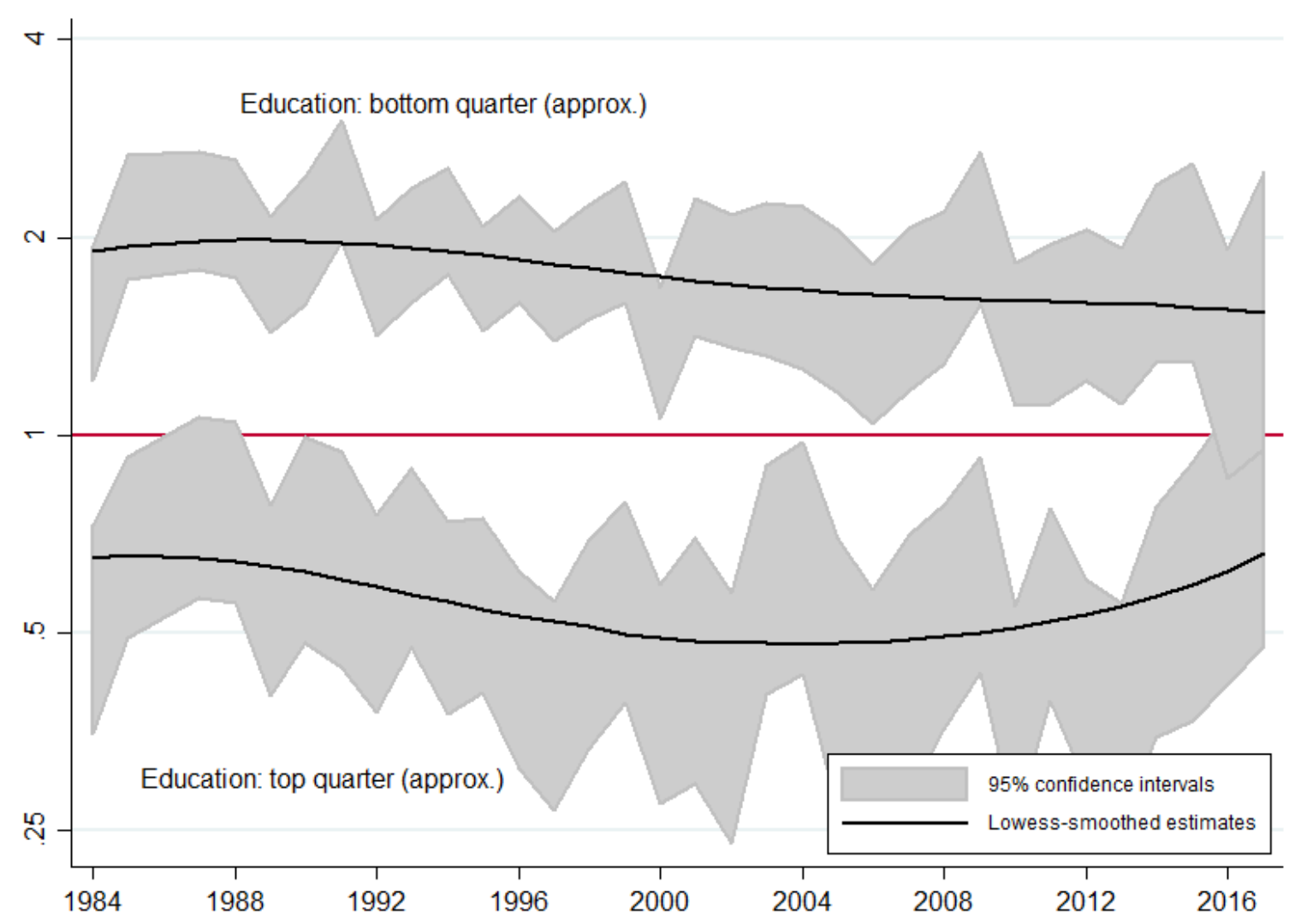

Figure 5 Age-adjusted risk ratios for being divorced/separated and unemployed (DSU), by education, women

Source: UK Labour Force Survey.

Figures 4 and 5 give clearer visualisations of the educational stratification of DSU over time. These figures plot risk ratios by education (taking the middle half as the reference group), adjusted for (mean-centred) age. The smoothed lines produced by locally-weighted regressions show a narrowing of educational stratification for men (Figure 4) in the period to 2000 , driven by both upper and lower quarters coming closer to the middle group in their risk of being DSU. In the 1980s, men in the lowest quarter by education are around five times as likely as those in the highest to be DSU, but this falls to around three or four for the rest of the period. For women (Figure 5), the risk ratio for the bottom versus the top educational quarter is stable at around three or four, but there is some change in the trends of each relative to the middle half. The higher-educated women diverge slightly from the middle group in the 
middle part of the period, but converge later on, with the confidence intervals for both top and bottom quarters for 2017 including a risk ratio of 1 . The overall picture is of quite stable and strong educational stratification in DSU.

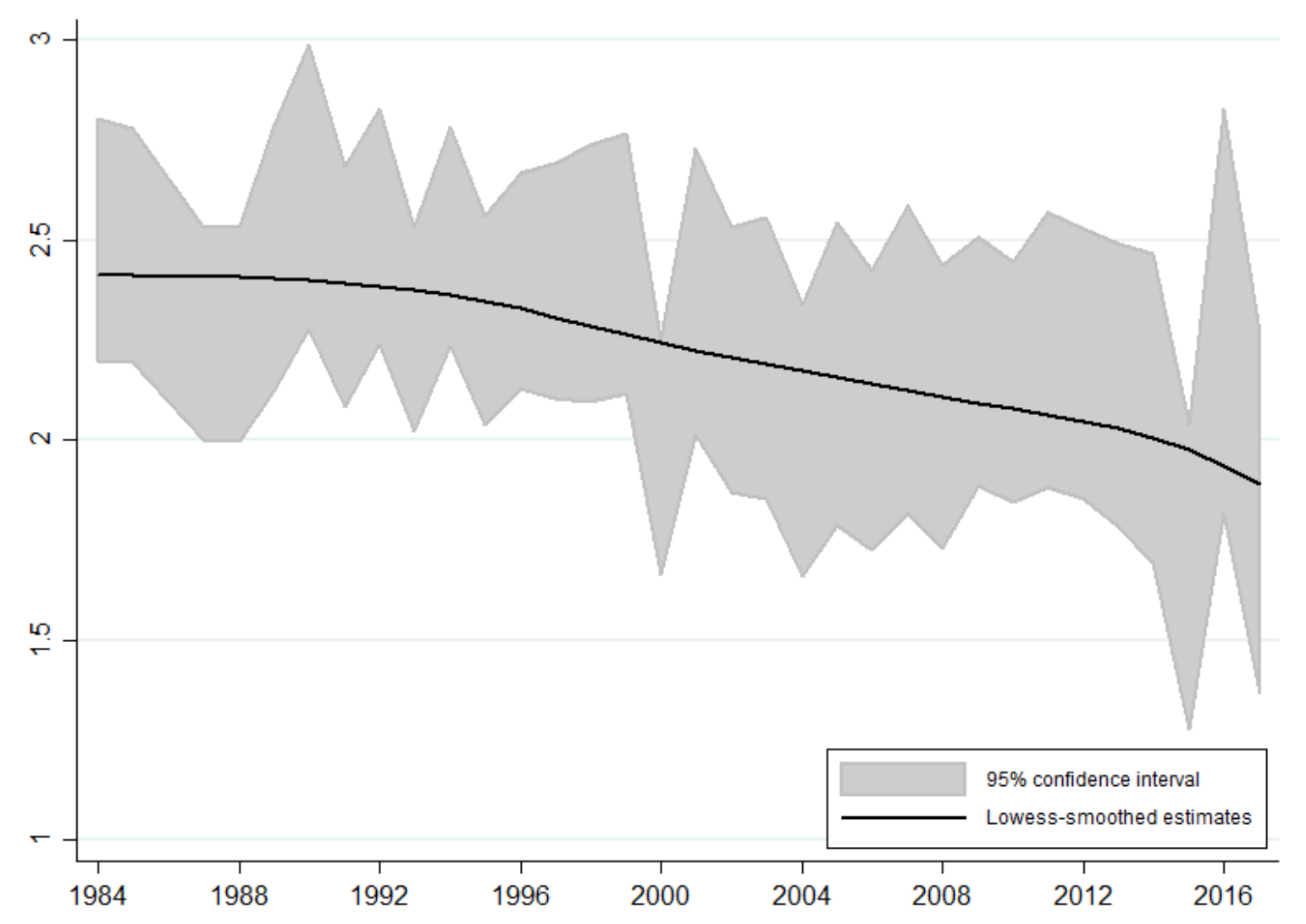

Figure 6 Association between being unemployed and being divorced/separated (age-adjusted odds ratio), men

Source: UK Labour Force Survey. 


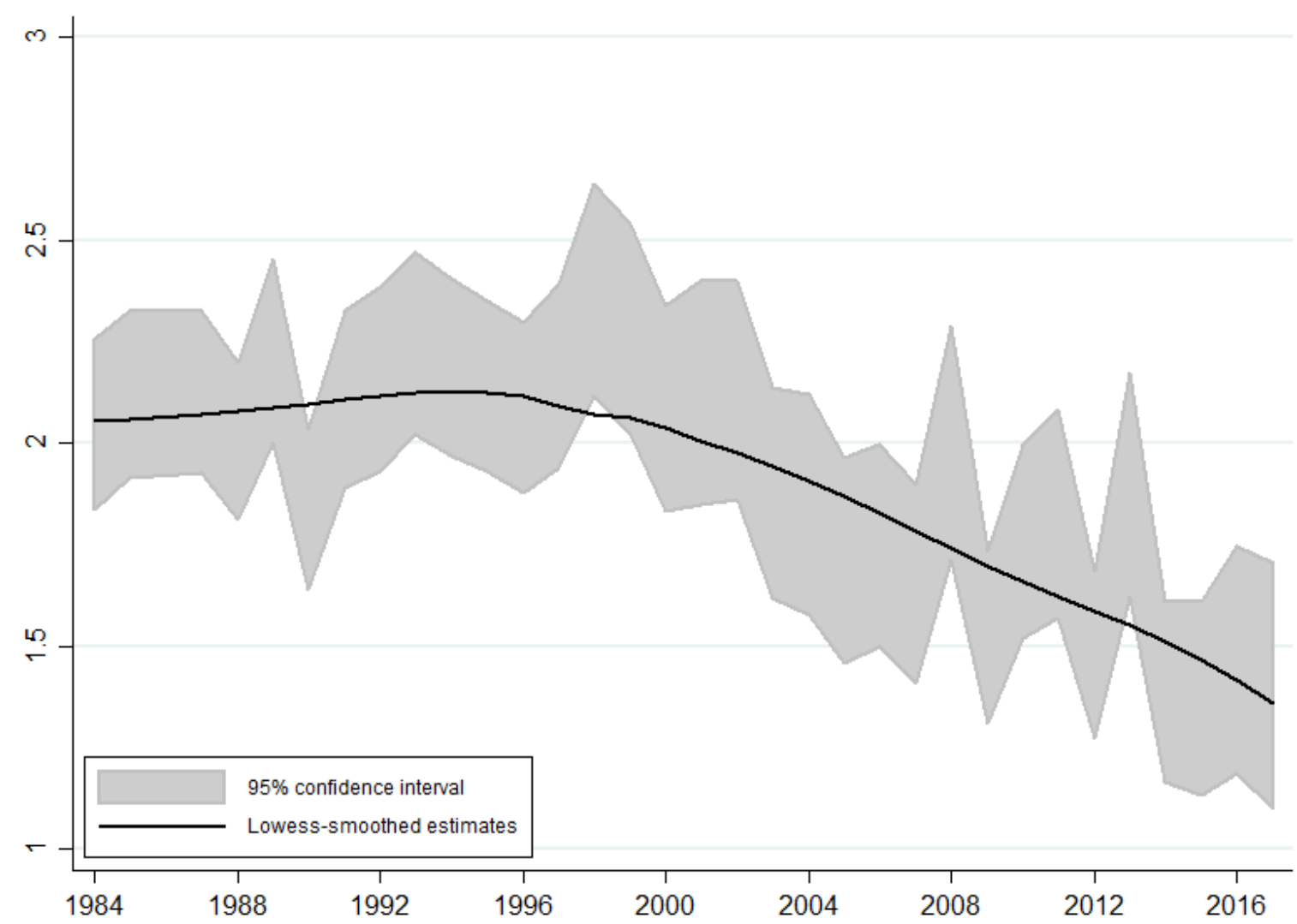

Figure 7 Association between being unemployed and being divorced/separated (age-adjusted odds ratio), women

Source: UK Labour Force Survey.

Next we turn to the cross-sectional association between the two states, expressed as an odds ratio. Compared to someone who is not unemployed (alternatively, divorced/separated), how likely is someone who is unemployed (divorced/separated) to be divorced/separated (unemployed)? Figures 6 and 7 reveal two important findings. First, the cross-sectional association between the two states is consistently stronger among men than among women. Second, it has declined substantially between 1984 and 2017, and particularly for women. Individuals who are unemployed are decreasingly likely to also be divorced/separated. For someone who is unemployed, the odds of (also) being divorced/separated (and thus DSU) are $76 \%$ greater for men and $37 \%$ greater for women in 2017 , compared with someone who is not unemployed. The same is true if one considers the contrast between an individual who is 
divorced/separated and one who is not, in terms of their odds of (also) being unemployed. In 1984, these figures were $148 \%$ for men and $103 \%$ for women. For men the decline appears fairly constant through the period, though perhaps slight from 1984 to around 1996. For women, there is more clearly a turning point: prior to 1998 , there is no sign of a decrease in the association, but from 1998 onwards it is clear and steep.

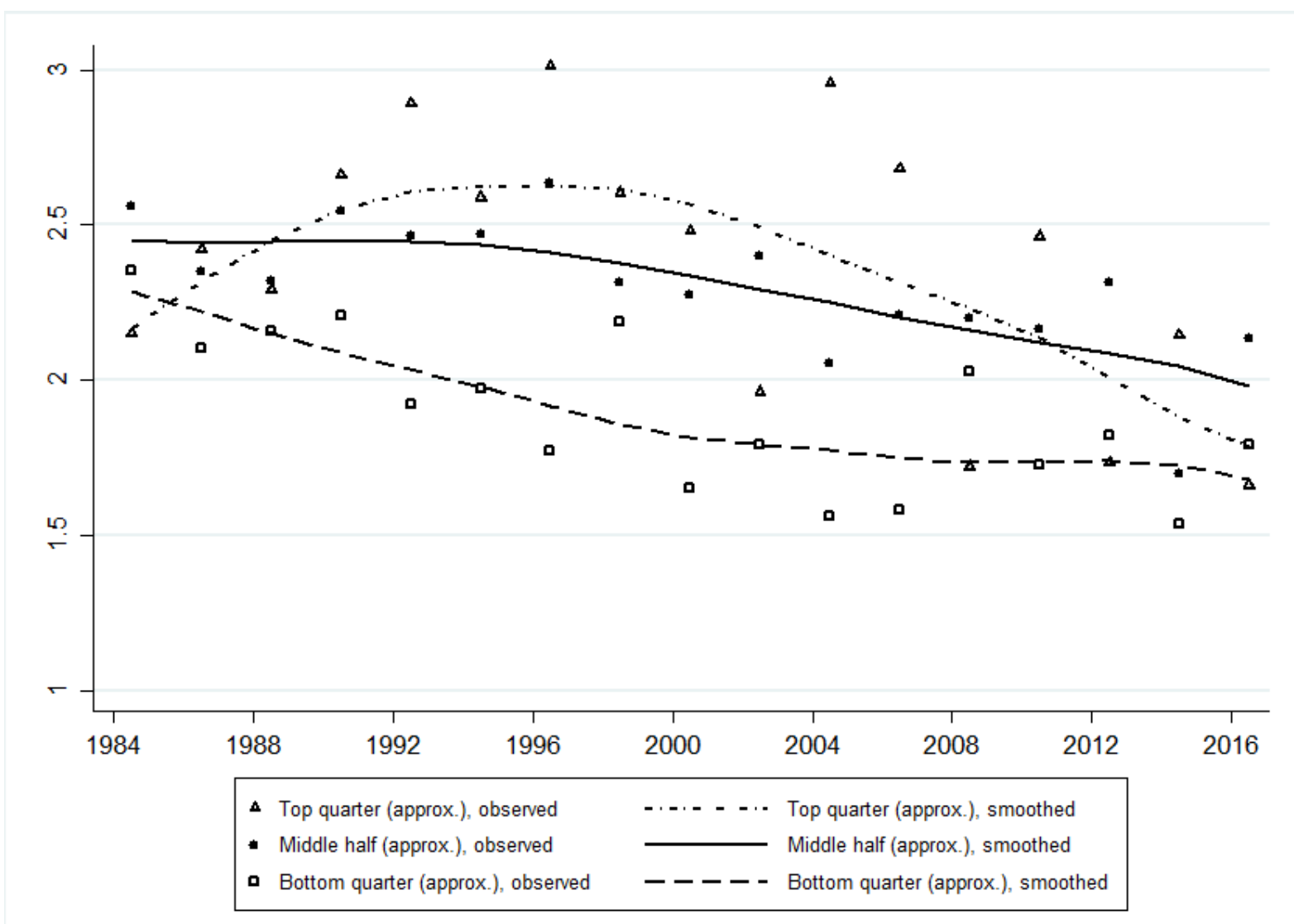

Figure 8 Association between being unemployed and being divorced/separated (age-adjusted odds ratio), men, by education Source: UK Labour Force Survey. 


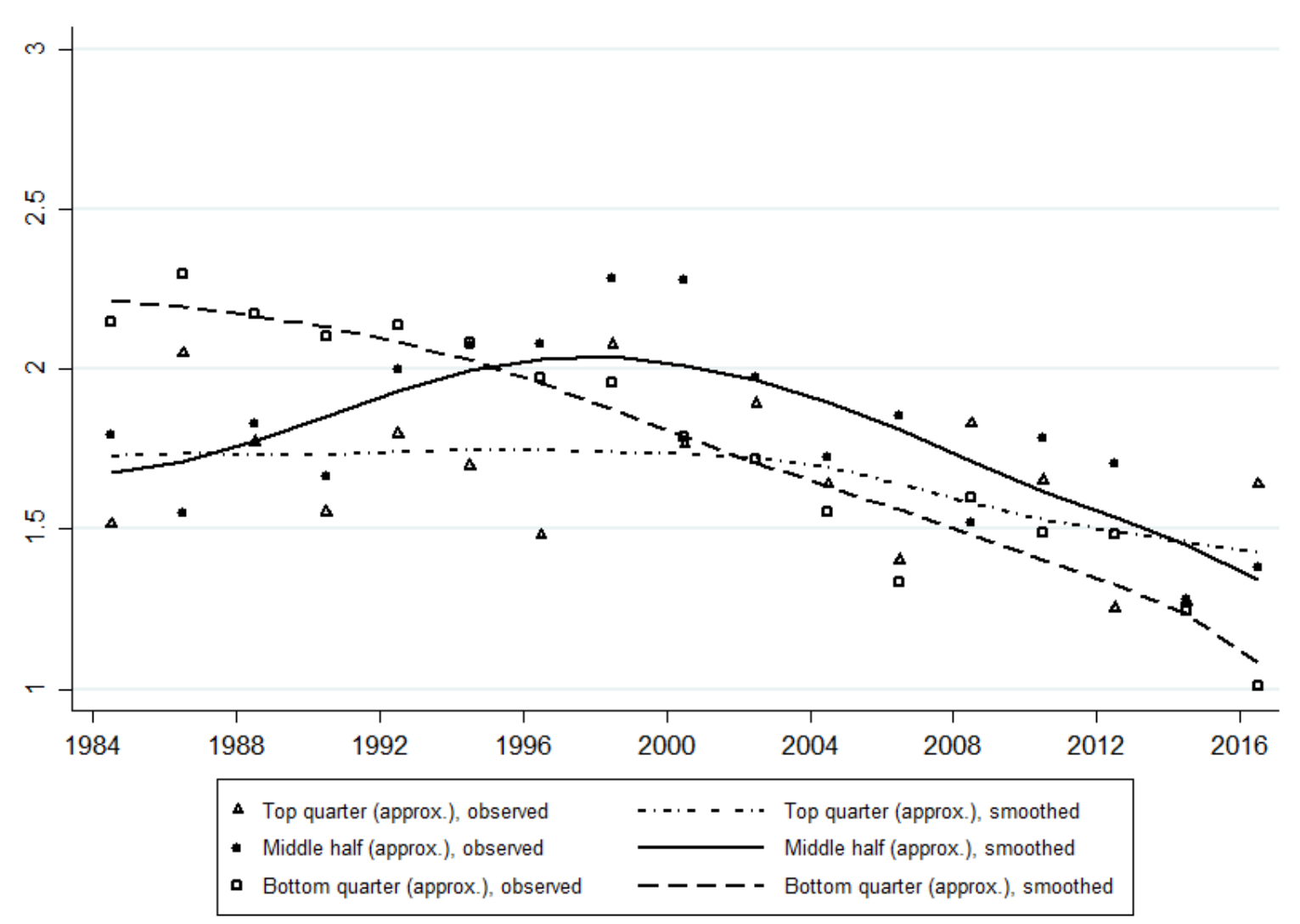

Figure 9 Association between being unemployed and being divorced/separated (age-adjusted odds ratio), women, by education Source: UK Labour Force Survey.

In Figures 8 and 9, disaggregating the cross-sectional association by education, we group the data into pairs of years $(1984-85,1986-87$ etc.) to make the visualisation clearer. Across the period as a whole, the weakening of the association is evident among each of the sex-education groups, although the group of higher-educated women show only a faint trend of decline, and a relatively low association throughout. The timing and intensity of the decline varies between groups, however. Among men, there is stability or even an increase in the first half of the period among middle- and high-educated men. For these groups, the decline comes later, and is especially steep among the high-educated. Among the lesseducated, the pattern is the reverse: there is a steep decline until around 2004 and then a levelling-off. The pattern is rather similar for women: stability or increase among the middle- 
and high-educated in the first half, with the decline coming later, though more for the middleeducated; and a steep decline among the less-educated, which unlike for men, continues through the whole period.

Though there is volatility between years, generally there is a clear educational gradient among men. For most of the period, the two component states are more closely associated among the higher-educated men, and clearly less closely associated among the lower-educated. With regard to the most educated, this pattern is however absent at the beginning and end of the period. Recall that the proportion DSU is lowest among the most educated men, which may account for the volatility of the estimates between years for that group. The gap between the lower-educated and middle-educated is substantial and present through the whole period, suggesting an educational gradient is present. Among women, by contrast, the three educational groups are relatively equal throughout, except that the two states may be more strongly linked among less educated women in the beginning of the period. 
(a) Men, divorced/separated

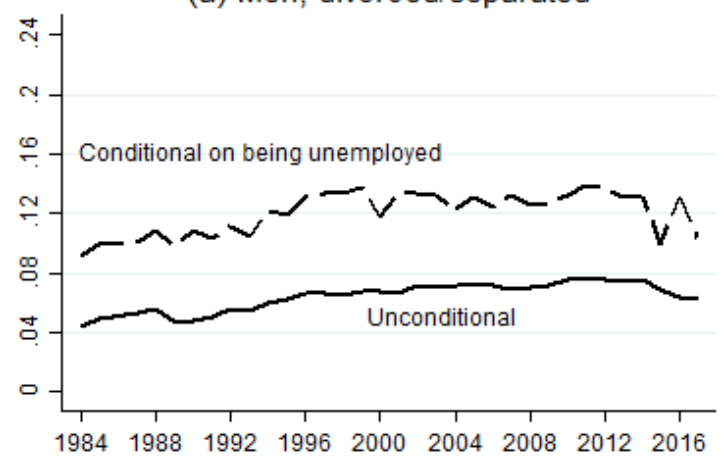

(c) Men, unemployed

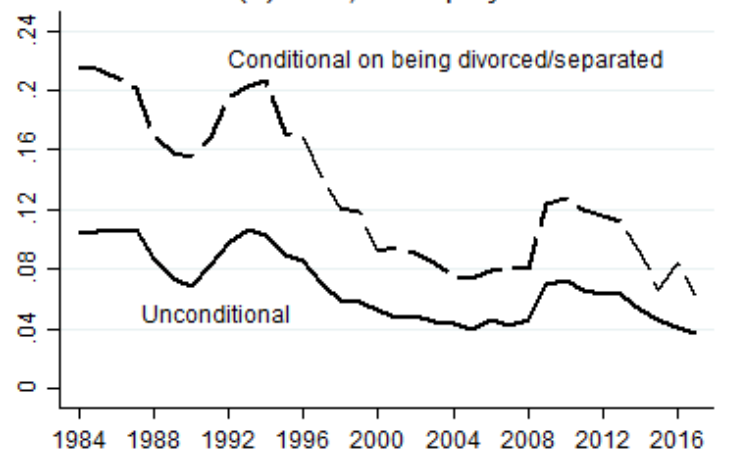

(b) Women, divorced/separated

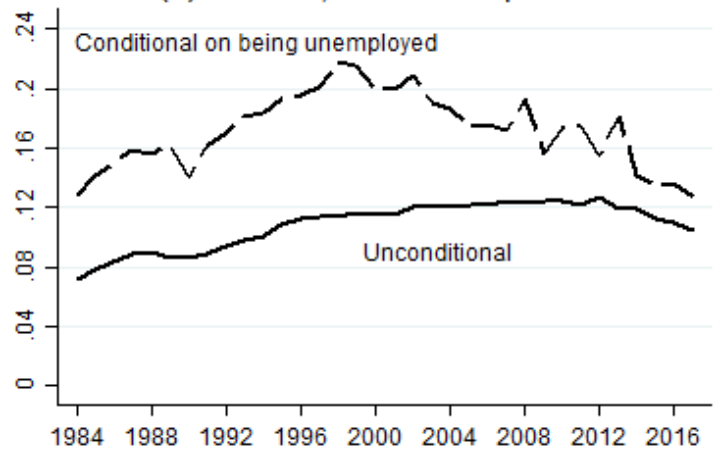

(d) Women, unemployed

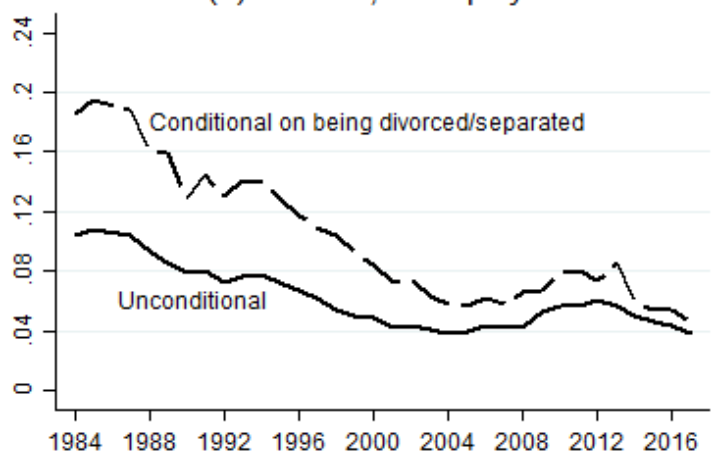

Figure 10 Proportion divorced/separated and proportion unemployed, unconditional and conditional on being in the other state

Source: UK Labour Force Survey.

What might be driving this loosening of the association between the two states? Figure 10 shows the proportion who are divorced/separated, conditional on being unemployed, and vice versa. For men, the proportion divorced/separated is steadily greater among the unemployed than among the general population (panel (a)). In each of panels (b)(d), however, we see a convergence of the lines indicating a loosening of the dependence between the two states. This is most pronounced with regard to the proportions who are unemployed (panels (c) and (d)). The proportion unemployed among adults in general, and the proportion unemployed among those who are divorced/separated have almost fully converged. This suggests that the association between the two states is primarily being driven down by an increase in the number of divorced/separated individuals for reasons unrelated to 
changes in the proportion unemployed; that is, the divorced/separated are becoming more like the general population, rather than a selected subgroup among whom unemployment is a particular risk. However, the unemployed, particularly unemployed men, steadily remain a group whose risk of being divorced/separated is clearly higher than the general population. These patterns are the same for each of the groups disaggregated by sex and education (Figures A3 and A4).

\subsection{Robustness check}

Our definition of unemployment diverges from the ILO version used by official statistics agencies. Figures A5-A14 in the supplemental material replicate Figures 1-10, extending the time series back to 1979 and using the ILO definition of unemployment (and, from 19791984 , its close equivalent except that the job-seeking activity requirement is with reference to the previous week rather than previous four weeks). In comparing the sets of figures it is important to bear in mind the slight extension of the time period. Beyond the obviously slightly lower levels of unemployment under the more restrictive ILO definition, the main difference between the two measures is seen among women in the 1980s, with lower levels relative to men than in the main analysis, and a surprising lack of inequality between the middle and bottom by education (Figure A6). Given the high unemployment rate in this period, we suspect that the ILO measure misses a substantial number of women, especially those lacking any qualifications, who would have welcomed work but in that climate made the judgement that actively seeking a job would be unlikely to result in success. These findings do not alter our substantive conclusions. 


\subsection{Supplemental analyses}

Some further noteworthy results are briefly presented here. First, Figure A15 shows, for 1995-2017, the cross-sectional association (as in Figures 6-9), comparing results for two subsets of the divorced/separated - those not currently cohabiting, and those who are currently cohabiting. The difference is stark: there is no association between being divorced/separated and being unemployed amongst those who now live together with someone as a couple. This highlights the importance of the actual presence or absence of a partner versus legal marital status. A number of interpretations are possible, but none can be given with confidence due to our lack of information about the ordering of events. For instance, this may be confounded by time since marital dissolution, may reflect unobserved characteristics, or may be due to a positive impact of repartnering on re-entry into employment. This result has another important implication. Our data for 1984-1988 include both of these two groups as divorced/separated (see above). It is therefore likely that our estimation of the cross-sectional association in this early part of the period is biased downward by the inclusion of the now-cohabiting, amongst whom Figure A15 suggests there is no cross-sectional association. The decline across the whole period is thus likely to be somewhat steeper than Figures 6-9 suggest.

Figures A16 and A17 explore the age distribution among the DSU and those in the two component states. The median age of the DSU has risen substantially among men in particular, from 43 to 55 . Among women it has risen from 41 to 48 . This mirrors an upward shift in the age distribution of the divorced/separated. The age distribution of the unemployed, which shows a greater dispersion, has remained stable, with the median fluctuating around 40-45 among men and around 40 for women. The divergence in the age distributions of those in the two component states of DSU may be a mechanism driving the 
decline in the cross-sectional association. The reasons behind this are a topic for future research, but we speculate that as individuals increasingly delay entry into marriage and are subsequently older when at risk of divorce, they increasingly distance themselves from the age range around which unemployment risk is greatest.

\section{Discussion}

The aim of this paper was to answer basic descriptive questions about the co-prevalence of being divorced/separated and unemployed, a joint state theoretically expected to be extremely disadvantageous as well as difficult to exit, but about which we know almost nothing. We leverage the large sample size and long temporal coverage of the LFS series to examine trends in and stratification of DSU and the cross-sectional association between its two component states.

Our first research question concerned the proportion of the adult population which is DSU, and how this has changed over time. With the proportion divorced/separated rising through the period to a peak around 2010, and unemployment showing a clear decline punctuated by economic crises, the trend in DSU is by no means a priori clear. In fact, there has been a decline, following the trend of unemployment, but tempered by the rising proportion of individuals divorced/separated. Over the period from 1984-2017, the proportion DSU peaked at 1.2\% among men in 1994, and at 1.6\% among women in 1987. In 2017 it stood at around $0.4 \%$ among both men and women, amounting to around 150,000 individuals.

Our second question concerned stratification in the risk of DSU according to gender and relative educational attainment. We expected that DSU would be concentrated among the less educated, but held no prior expectations about gender differences. As expected, those in the bottom quarter of the educational distribution relative to those of the same sex and similar 
age were most at risk of DSU. This inequality was especially wide among men in the 1980s during a period of very high unemployment among less educated men in particular. For most of the period, women were more likely to be DSU than men, across the educational distribution. However this gender difference has decreased and even disappeared.

Our third question concerned the cross-sectional association between the states of being divorced/separated and being unemployed. This refers to how predictive being in one state is of (also) being in the other (and thus DSU). We expected that this relationship might be strongest among the less educated. The cross-sectional association can be influenced by factors affecting the likelihood of job loss conditional on being divorced/separated, of marital dissolution conditional on being unemployed, of gaining a job conditional on being divorced/separated, or of repartnering conditional on being unemployed. We speculated that the less educated might be at a particular disadvantage when looking for a new partner whilst unemployed, and might also be more likely to experience marital dissolution whilst unemployed, given that the unemployed with more education on average have better earnings prospects which might be attractive to a new or existing partner. We again had no clear expectations about gender differences, with plausible mechanisms operating in opposite directions.

With regard to this third question, our main findings are that the association is stronger among men, educationally stratified among men (weakest among the least educated men) but not among women, and has weakened substantially between 1984 and 2017. Indeed the point estimate for the cross-sectional association in 2016-17, among the least educated approximate quarter of women, is an odds ratio of 1.01, down from 2.14 in 1984-85: remarkably, among this group, the most recent results indicate that being divorced/separated and being unemployed are uncorrelated states. 
The finding that the association is consistently stronger amongst men likely reflects a persistence of the norm that husbands should be breadwinners (Forret, Sullivan, and Mainiero 2010; Sayer et al. 2011). Kalmijn (2005) has documented negative labour market consequences of divorce for men, and Covizzi (2008) finds a stronger impact of union dissolution on risk of unemployment for men than for women. It is likely too that unemployment is a particular obstacle to repartnering for men, both because of the breadwinner norm and because the workplace is one of the main contexts within which men meet potential partners in the remarriage market (de Graaf and Kalmijn 2003). Although men may be especially vulnerable to unemployment following a divorce, a consistent finding has been that women suffer a greater loss of income (Andreß et al. 2006; Leopold 2018). Another explanation for the gender inequality may then be that women have stronger incentives to either repartner or enter employment if they are in the state of being DSU (Jansen, Mortelmans, and Snoeckx 2009). Women across all social strata usually take on childcare responsibilities post-divorce. Sole responsibility for childcare may increase the urgency of repartnering or employment, or lead to a transition out of the labour force.

Educational stratification in the association between the two states is not clearly evident among women, except in the early part of the period when being divorced/separated and unemployed were more closely linked among less educated women. For men there is a clearer gradient, with the association strongest amongst those with higher educational attainment. One possible explanation for this is that the group of high educated men who are in one of the two states are relatively more negatively selected on unobserved characteristics, such as poor health or certain personality traits, which might make being (and remaining) both unemployed and divorced/separated more likely. Among less educated men, unemployment may be less of a signal of such characteristics, being both a more prevalent state and one which is more likely than among higher educated men to owe (more) to the 
employer than the employee. Indeed Doiron \& Mendolia find that the effect of male job loss on divorce varies on this dimension, with redundancies, interpreted as more likely to be exogenous, having 'small, positive, often insignificant and short-lived effects' on divorce (2012: 367), while more person-specific types of job loss such as dismissals have larger impacts. The authors' interpretation is that this is because person-specific types of job loss convey new information about the (poor) quality of a match. It is also possible that for more educated men, unemployment results in a greater decline in earnings capacity and career prospects, leading in turn to a greater risk of marital dissolution compared with the less educated.

Using data from 2002-2017, we are able to test the hypothesis that higher educated DSU men are more negatively selected on health grounds. This does not appear to be the case. At least by our measure - having a health problem lasting more than 12 months - the most educated are no more likely than the other groups to be unhealthy. We cannot rule out negative selection on other characteristics.

An alternative explanation for the educational pattern is that higher educated men are more tolerant of DSU, in a range of possible ways. First, they may have the resources and preference to tolerate a longer job search period while they try to re-enter employment in a relatively high status occupation. Their repartnering behaviour may be analogous. Less educated men, with fewer resources, may seek immediate exit from DSU status on both fronts, and be more likely to seek and find the type of employment that is immediately available. In addition, less educated men, with fewer coping resources, may be more likely to exit DSU not by entering employment but by leaving the labour force, if the stress of divorce causes or exacerbates health problems. Some report that the process of separation and divorce is more stressful for men than women (Amato 2000). 
Most notably, there has been a clear decline in the association between the two states across both sexes and all educational strata within them, except among the most educated quarter of women, among whom the association has consistently been relatively weak. The proportion unemployed among the divorced/separated has declined relative to the proportion unemployed in general, while the proportion divorced/separated among the unemployed has remained more stable relative to the general population (Figure 10). The association is primarily being driven down by the divorced/separated increasingly resembling the rest of the population in terms of their risk of being unemployed. This overall decline in the association between the two states is therefore consistent with a rise in divorce and separation for reasons unrelated to unemployment and its determinants. We speculate that this declining association may therefore be due in large part to a general weakening of the social norm against divorce and separation in the UK. Related research on attitudes towards marriage suggests a strong, steady decline in traditional attitudes in this area (NatCen 2016). In 1989, 70\% agreed that 'people who want children ought to get married' and under $20 \%$ disagreed. By 2014 , these figures were $37 \%$ and $35 \%$ respectively. Acceptance of childbearing outside of wedlock is likely to closely correlate with acceptance of divorce, which regularly occurs between couples with children.

A second factor loosening the association between the two states may be policy. As discussed above, 1998 saw the introduction of New Labour reforms aimed at 'making work pay', and which had the effect of keeping a substantial proportion of separated women in employment. This coincides with beginning of the steep decline in the association among women, shown in Figure 7. A third possible factor is that the increasing delay of entry into marriage may be leading to divergent age distributions among those most at risk of being divorced/separated and those most at risk of being unemployed, as suggested by our 
supplemental analysis. A fuller explanation of this decline would be a useful target for future research.

There are clear limitations to this study: inter alia, our analysis is restricted exclusively to the UK. Many of the processes underlying the generation of DSU are likely to be context dependent, reflecting macroeconomic conditions, labour market policy, barriers and incentives to divorce, and social norms governing the interpretation of the signals constituted by being divorced/separated in the labour market, and by being unemployed in the search for a new partner. Our data do not contain good quality, consistent measures of the outcomes DSU might be theorised to relate to. They also do not contain any longitudinal information. We are not able to ask any questions of the particular sequences or mechanisms by which individuals become, remain, and cease to be DSU, and nor do we know individuals' DSU duration.

It might be argued that with the rise of cohabitation, and lower rates of marriage, the phenomenon of marital dissolution in particular is of declining interest, and we should attend also to the dissolution of cohabiting unions. We are constrained to explore marital dissolution exclusively because the data do not record the state of being separated from a cohabiting relationship. However, we also believe that marital dissolution is a loss event distinct from the dissolution of a cohabiting relationship. The latter is more likely to be viewed more as a failed experiment, an iteration in the matching process. Marriage, by contrast, is obviously intended at the outset to be a long-term commitment, the culmination of the matching process. Given that, increasingly, a couple might merely cohabit, marriage represents a particularly strong commitment, and its dissolution a particularly pronounced negative event, in most cases.

This paper provides an impetus for further work on the processes of DSU entry and exit, and how they vary among groups. The existing literature is relatively uninformative 
about gender and, in particular, educational stratification in the processes that generate the cross-sectional association between being divorced/separated and unemployed, and thus their co-prevalence. Among the unemployed seeking to save their marriage or find a new partner, and among the divorced/separated seeking to hold on to their job or find a new one, how does education matter? A substantial number of individuals remain in the 'wellbeing trap' of DSU; future research might usefully explore how they can escape. 


\section{References}

Amato, Paul R. 1996. 'Explaining the Intergenerational Transmission of Divorce'. Journal of Marriage and Family 58(3):628-40.

Amato, Paul R. 2000. 'The Consequences of Divorce for Adults and Children'. Journal of Marriage and Family 62(4):1269-87.

Andreß, Hans-Jürgen, Barbara Borgloh, Miriam Bröckel, Marco Giesselmann, and Dina Hummelsheim. 2006. 'The Economic Consequences of Partnership Dissolution-A Comparative Analysis of Panel Studies from Belgium, Germany, Great Britain, Italy, and Sweden'. European Sociological Review 22(5):533-60.

Bernasco, Wim, Paul M. de Graaf, and Wout C. Ultee. 1998. 'Coupled Careers: Effects of Spouse's Resources on Occupational Attainment in the Netherlands'. European Sociological Review 14(1):15-31.

Blekesaune, Morten. 2008. Unemployment and Partnership Dissolution. Working Paper. 2008-21. ISER Working Paper Series.

Blossfeld, H., A. de Rose, J. M. Hoem, and G. Rohwer. 1995. 'Education, Modernization, and the Risk of Marriage Disruption in Sweden, West Germany, and Italy'. Pp. 200222 in Gender and Family Change in Industrialized Societies, edited by K. O. Mason and A. Jensen. Oxford: Clarendon Press.

Boertien, Diederik and Dimitri Mortelmans. 2017. 'Does the Relationship between Personality and Divorce Change over Time? A Cross-Country Comparison of Marriage Cohorts'. Acta Sociologica 0001699317709048. 
Bracher, Michael, Gigi Santow, S. Philip Morgan, and James Trussell. 1993. 'Marriage Dissolution in Australia: Models and Explanations'. Population Studies 47(3):403-25.

Brand, Jennie E. 2015. 'The Far-Reaching Impact of Job Loss and Unemployment'. Annual Review of Sociology 41(1):359-75.

Brandolini, Andrea, Piero Cipollone, and Eliana Viviano. 2006. 'Does the ILO Definition Capture All Unemployment?' Journal of the European Economic Association 4(1):153-79.

Caspi, Avshalom, Bradley R. Entner Wright, Terrie E. Moffitt, and Phil A. Silva. 1998. 'Early Failure in the Labor Market: Childhood and Adolescent Predictors of Unemployment in the Transition to Adulthood'. American Sociological Review 63(3):424-51.

Chan, T. W. and B. Halpin. 2008. The Instability of Divorce Risk Factors in the UK. Working Paper. Oxford: Department of Sociology, University of Oxford.

Covizzi, Ilaria. 2008. 'Does Union Dissolution Lead to Unemployment? A Longitudinal Study of Health and Risk of Unemployment for Women and Men Undergoing Separation'. European Sociological Review 24(3):347-61.

Dewilde, Caroline and Wilfred Uunk. 2008. 'Remarriage as a Way to Overcome the Financial Consequences of Divorce-A Test of the Economic Need Hypothesis for European Women'. European Sociological Review 24(3):393-407.

DiPrete, Thomas A. and Gregory M. Eirich. 2006. 'Cumulative Advantage as a Mechanism for Inequality: A Review of Theoretical and Empirical Developments'. Annual Review of Sociology 32(1):271-297. 
Doiron, Denise and Silvia Mendolia. 2012. 'The Impact of Job Loss on Family Dissolution'. Journal of Population Economics 25(1):367-98.

Dolan, Paul, Tessa Peasgood, and Mathew White. 2008. 'Do We Really Know What Makes Us Happy? A Review of the Economic Literature on the Factors Associated with Subjective Well-Being'. Journal of Economic Psychology 29(1):94-122.

Egan, Mark, Michael Daly, Liam Delaney, Christopher J. Boyce, and Alex M. Wood. 2017. 'Adolescent Conscientiousness Predicts Lower Lifetime Unemployment'. The Journal of Applied Psychology 102(4):700-709.

Ehlert, Martin. 2012. 'Buffering Income Loss Due to Unemployment: Family and Welfare State Influences on Income after Job Loss in the United States and Western Germany’. Social Science Research 41(4):843-60.

Eurostat. 2018a. 'Crude Divorce Rate, Selected Years, 1960-2016'. Eurostat - Statistics Explained. Retrieved 17 July 2018 (http://ec.europa.eu/eurostat/statisticsexplained/index.php?title=File:Crude_divorce_rate,_selected_years,_19602016_(per_1_000_persons).png).

Eurostat. 2018b. 'Unemployment Rate - Annual Data'. Eurostat - Tables, Graphs and Maps $\begin{array}{lllll}\text { Interface } & (T G M) . & \text { Retrieved } & 15 & \text { July }\end{array}$ (http://ec.europa.eu/eurostat/tgm/graph.do?tab=graph\&plugin=1\&pcode=tipsun20\&la nguage $=$ en $\&$ toolbox $=$ sort $)$.

Forret, Monica L., Sherry E. Sullivan, and Lisa A. Mainiero. 2010. 'Gender Role Differences in Reactions to Unemployment: Exploring Psychological Mobility and Boundaryless Careers'. Journal of Organizational Behavior 31(5):647-66. 
Goldthorpe, John H. 2016. Sociology as a Population Science. Cambridge: Cambridge University Press.

de Graaf, Paul M. and Matthijs Kalmijn. 2003. 'Alternative Routes in the Remarriage Market: Competing-Risk Analyses of Union Formation after Divorce'. Social Forces 81(4):1459-98.

de Graaf, Paul M. and Matthijs Kalmijn. 2006. 'Change and Stability in the Social Determinants of Divorce: A Comparison of Marriage Cohorts in the Netherlands'. European Sociological Review 22(5):561-572.

Hansen, Hans-Tore. 2005. 'Unemployment and Marital Dissolution - A Panel Data Study of Norway'. European Sociological Review 21(2):135-48.

Härkönen, Juho and Jaap Dronkers. 2006. 'Stability and Change in the Educational Gradient of Divorce. A Comparison of Seventeen Countries'. European Sociological Review 22(5):501-17.

Hoem, Jan M. 1997. 'Educational Gradients in Divorce Risks in Sweden in Recent Decades'. Population Studies 51(1):19-27.

Jackson, Pamela Braboy and Alexandra Berkowitz. 2005. 'The Structure of the Life Course: Gender and Racioethnic Variation in the Occurrence and Sequencing of Role Transitions'. Advances in Life Course Research 9:55-90.

Jalovaara, Marika. 2003. 'The Joint Effects of Marriage Partners' Socioeconomic Positions on the Risk of Divorce'. Demography 40(1):67-81. 
Jansen, Mieke, Dimitri Mortelmans, and Laurent Snoeckx. 2009. 'Repartnering and (Re)Employment: Strategies to Cope With the Economic Consequences of Partnership Dissolution'. Journal of Marriage and Family 71(5):1271-93.

Jenkins, Stephen P. 2008. Marital Splits and Income Changes over the Longer Term. ISER Working Paper Series 2008-07. Institute for Social and Economic Research, University of Essex.

Kalmijn, Matthijs. 2005. 'The Effects of Divorce on Men's Employment and Social Security Histories'. European Journal of Population / Revue Européenne de Démographie 21(4):347-66.

Kalmijn, Matthijs, Paul M. de Graaf, and Anne-Rigt Poortman. 2004. 'Interactions Between Cultural and Economic Determinants of Divorce in The Netherlands'. Journal of Marriage and Family 66(1):75-89.

Killewald, Alexandra. 2016. 'Money, Work, and Marital Stability: Assessing Change in the Gendered Determinants of Divorce'. American Sociological Review 81(4):696-719.

Kreidl, Martin and Barbora Hubatková. 2017. 'Rising Rates of Cohabitation and the Odds of Repartnering: Does the Gap Between Men and Women Disappear?' Journal of Divorce \& Remarriage 58(7):487-506.

Lampard, Richard. 1994. 'An Examination of the Relationship between Marital Dissolution and Unemployment'. Pp. 264-98 in Social Change and the Experience of Unemployment, edited by D. Gallie, C. Marsh, and C. Vogler. Oxford: Oxford University Press. 
Leopold, Thomas. 2018. 'Gender Differences in the Consequences of Divorce: A Study of Multiple Outcomes'. Demography 55(3):769-97.

Long, Katy. 2009. 'Unemployment Durations: Evidence from the British Household Panel Survey'. Economic \& Labour Market Review 3(10):48-54.

Lyngstad, Torkild. 2004. 'The Impact of Parent's and Spouses' Education on Divorce Rates in Norway’. Demographic Research 10(5):121-42.

Matthews, Karen A. and Brooks B. Gump. 2002. 'Chronic Work Stress and Marital Dissolution Increase Risk of Posttrial Mortality in Men from the Multiple Risk Factor Intervention Trial'. Archives of Internal Medicine 162(3):309-15.

McDonough, Peggy, Diana Worts, Cara Booker, Anne McMunn, and Amanda Sacker. 2015. 'Cumulative Disadvantage, Employment-Marriage, and Health Inequalities among American and British Mothers'. Advances in Life Course Research 25:49-66.

McMunn, Anne et al. 2015. 'De-Standardization and Gender Convergence in Work-Family Life Courses in Great Britain: A Multi-Channel Sequence Analysis'. Advances in Life Course Research 26:60-75.

Merton, Robert K. 1987. 'Three Fragments From a Sociologist's Notebooks: Establishing the Phenomenon, Specified Ignorance, and Strategic Research Materials'. Annual Review of Sociology 13(1):1-29.

NatCen. 2016. 'Is Britain Getting a Divorce from Marriage?' NatCen Social Research. Retrieved $16 \quad$ July $2018 \quad$ (http://www.natcen.ac.uk/news-media/pressreleases/2016/may/attitudes-to-marriage/). 
ONS. 2017. 'Statistical Bulletin: Divorces in England and Wales: 2016'. Office for National $\begin{array}{lllll}\text { Statistics. } & \text { Retrieved } & 15 & \text { July } & 2018\end{array}$ (https://www.ons.gov.uk/peoplepopulationandcommunity/birthsdeathsandmarriages/d ivorce/bulletins/divorcesinenglandandwales/2016).

Özcan, Berkay and Richard Breen. 2012. 'Marital Instability and Female Labor Supply'. Annual Review of Sociology 38(1):463-81.

Powdthavee, Nattavudh. 2012. 'Jobless, Friendless and Broke: What Happens to Different Areas of Life Before and After Unemployment?' Economica 79(315):557-75.

Price, Richard H., Jin Nam Choi, and Amiram D. Vinokur. 2002. 'Links in the Chain of Adversity Following Job Loss: How Financial Strain and Loss of Personal Control Lead to Depression, Impaired Functioning, and Poor Health'. Journal of Occupational Health Psychology 7(4):302-12.

Sayer, Liana C., Paula England, Paul D. Allison, and Nicole Kangas. 2011. 'She Left, He Left: How Employment and Satisfaction Affect Women's and Men's Decisions to Leave Marriages'. American Journal of Sociology 116(6):1982-2018.

Shafer, Kevin and Spencer L. James. 2013. 'Gender and Socioeconomic Status Differences in First and Second Marriage Formation'. Journal of Marriage and Family 75(3):54464.

Solomon, Brittany C. and Joshua J. Jackson. 2014. 'Why Do Personality Traits Predict Divorce? Multiple Pathways through Satisfaction'. Journal of Personality and Social Psychology 106(6):978-96. 
Thoits, Peggy A. 2010. 'Stress and Health: Major Findings and Policy Implications'. Journal of Health and Social Behavior 51(1_suppl):S41-53.

Uysal, Selver Derya and Winfried Pohlmeier. 2011. 'Unemployment Duration and Personality'. Journal of Economic Psychology 32(6):980-92.

Wagner, Michael and Bernd Weiß. 2006. 'On the Variation of Divorce Risks in Europe: Findings from a Meta-Analysis of European Longitudinal Studies'. European Sociological Review 22(5):483-500.

Worts, Diana, Amanda Sacker, Anne McMunn, and Peggy McDonough. 2013. 'Individualization, Opportunity and Jeopardy in American Women's Work and Family Lives: A Multi-State Sequence Analysis'. Advances in Life Course Research 18(4):296-318.

Wu, Zheng and Christoph M. Schimmele. 2005. 'Repartnering after First Union Disruption'. Journal of Marriage and Family 67(1):27-36. 